\title{
¿VíCTIMAS O VICTIMARIAS? EL ROL DE LAS MUJERES EN LAS FARC. UNA APROXIMACIÓN DESDE LA TEORÍA DE GÉNERO*
}

Gloria Yaneth Castrillón Pulido**

\section{Resumen}

Este artículo surge a partir de una inquietud personal sobre cómo afecta el conflicto a las mujeres que hacen parte de las FArC. Aplicando la perspectiva de género, e intentando superar los estereotipos que representan a las mujeres como pacíficas y a los hombres como guerreros, se hace un análisis de los diferentes roles asignados a unos y a otras en esta organización, para determinar cuál es el papel que juegan ellas como combatientes. El interés primordial es hacer una reflexión sobre cómo podrán las guerrilleras superar las contradicciones, los vacíos y las rupturas que les deja su participación como cuerpos armados.
Palabras clave: conflicto armado, género, poder, FARC, guerrilleras.

\section{VICTIMS OR VICTIMIZERS? THE ROLE OF WOMEN IN THE FARC. A GENDER THEORY APPROACH}

\begin{abstract}
This article arises from a personal curiosity about how the armed conflict affects the women who are a part of the FARC. By applying the gender perspective and attempting to overcome the pacifist stereotypes that represent women and the warrior stereotypes
\end{abstract}

* Este artículo fue elaborado en marzo de 2013 (y actualizado para la presente publicación) como trabajo de grado para el Programa de Titulación Alternativa de la Maestría de Asuntos Internacionales de la Facultad de Finanzas, Gobierno y Relaciones Internacionales de la Universidad Externado de Colombia.

** Magíster en Asuntos Internacionales, editora de Investigaciones de la revista Cromos y colaboradora de El Espectador, Bogotá (Colombia).

Recibido: 2 de febrero de 2015 / Modificado: 18 de marzo de 2015 / Aceptado: 6 de abril de 2015.

Para citar este artículo

Castrillón Pulido, G. Y. (2014). ¿Víctimas o victimarias? El rol de las mujeres en las Farc. Una aproximación desde la teoría de género. OPERA, 16, pp. 77-95. DOI: 10.18601/16578651.n16.06 
that represent men, an analysis is done of the different roles assigned to men and women in the organization to determine the actual role that female combatants play in the conflict. The primary interest is to reflect on how female guerrillas can overcome the contradictions, voids and strains that are a direct result of their participation in the armed conflict.

Key words: Armed conflict, gender, power, FARC, female guerrillas.

\section{INTRODUCCIÓN}

La imagen de doce guerrilleras ataviadas con camisetas de las Fuerzas Armadas Revolucionarias de Colombia (FARC) —el 21 de noviembre de 2012 - lanzando vivas a esa organización a la entrada del Palacio de las Convenciones en La Habana (Cuba), donde se llevan a cabo las conversaciones entre representantes del Gobierno colombiano y delegados de ese grupo insurgente ${ }^{1}$, volvió a poner sobre el tapete la presencia de las mujeres en esta guerrilla. Ya durante el anterior proceso de paz, desarrollado en el Caguán entre 1998 y 2002, la atención de la opinión pública y de algunos analistas se había volcado sobre la aparición de combatientes muy jóvenes, uniformadas, armadas y obedeciendo a sus mandos en perfecta formación ${ }^{2}$.

En el caso más reciente, las guerrilleras fueron designadas por la organización para participar en un equipo de apoyo a la mesa de conversaciones que sesiona en la capital cubana. La sorpresa fue ver una delegación femenina casi equivalente a la mitad del grupo. Con el avance del proceso de diálogo, las insurgentes fueron cobrando mayor relevancia en la negociación, hasta el punto de hacer parte de la Subcomisión Técnica del Fin del Conflicto y la Subcomisión de Género ${ }^{3}$. Las imágenes recordaron una realidad que ha sido pocas veces analizada a fondo: las condiciones de militancia de casi la mitad de los integrantes de las FARC, que son mujeres ${ }^{4}$.

Organizaciones defensoras de derechos humanos nacionales e internacionales, entidades estatales y medios de comunicación han documentado durante los últimos años denuncias sobre abusos cometidos contra las guerrilleras, como aborto y esterilización forzados y esclavitud sexual. Esa ha sido la cara más visible de la participación de las

\footnotetext{
1 La proclama fue proferida minutos antes de iniciar el segundo día de conversaciones formales.
}

2 Hasta ese momento no había mucha información sobre la composición de la guerrilla ni sobre sus normas de comportamiento. Tampoco había evidencia del porcentaje de mujeres que la conformaban ni de su corta edad.

3 Ambas instancias fueron creadas y anunciadas por las partes el 22 de agosto de 2014. Es de anotar que de la primera hacen parte, en representación del Gobierno, dos mujeres: una civil y una teniente de navío de la Armada. Esta es la subcomisión que discute el cese al fuego bilateral y definitivo, y las condiciones del proceso de DDR. La segunda subcomisión fue creada para incluir la perspectiva de género en los tres borradores de acuerdo ya pactados y en los futuros acuerdos.

4 Diversas entidades del Estado e incluso fuentes de las FARC, calculan que el $40 \%$ de los integrantes son mujeres. 
mujeres como combatientes de las Farc. Pero no la única.

Según expertos como Elise Barth (2002), quien ha analizado los procesos de desmovilización de combatientes de África, "a pesar de que las mujeres son tan importantes como los hombres en la génesis y perpetuación de un conflicto armado, su rol ha sido a menudo trivializado" (p. 3). Ella seńala que en los análisis faltan las perspectivas de las mujeres y es probable que aspectos importantes del conflicto permanezcan ocultos por esa razón. De allí la importancia de analizar cómo se estructuran las relaciones entre los géneros y los mecanismos de ejercicio de poder en una organización político-militar, como las FARC.

Para este artículo se tendrá como base la definición de género de Jean Scott (1996), según la cual es

... un elemento constitutivo de las relaciones sociales basadas en las diferencias que distinguen los sexos y [el género] es una forma primaria de relaciones significantes de poder. Los cambios en la organización de las relaciones sociales corresponden siempre a cambios en las representaciones del poder, pero la dirección del cambio no es necesariamente en un solo sentido (p. 23).

Al sustentar que el género puede usarse para el análisis histórico en la política, Scott (1996) explica que los Estados desatan acciones para dominar a las mujeres, no porque tengan una ganancia inmediata, sino porque esas acciones cobran sentido como parte de un análisis de la construcción y la consolidación del poder: "Como política hacia las mujeres, se dio forma al mantenimiento del control de la fuerza [...] la diferencia sexual se concebía en términos de dominación y control a las mujeres" (p. 31).

La manera de lograr el control y, por ende, la dominación de la que habla la autora es propiciando y manteniendo una distribución desigual de conocimientos, propiedad, ingresos, responsabilidades y derechos entre mujeres y hombres. Es así como el género estructura unas relaciones asimétricas de poder entre ambos. En este sentido, es importante acoger la idea de Meertens (2000), según la cual:

... utilizar una lente de género para analizar fenómenos relacionados con la violencia no significa que se miren mujeres y se olviden los hombres, ni que el sexo de víctimas o victimarios les convierta en casos de mayor o menor importancia. Al contrario, el lente de género permite enfocar las cambiantes relaciones de hombres y mujeres y las diferentes, y también cambiantes, representaciones de la identidad de ambos en un contexto de violencia (p. 37).

Recogiendo la afirmación de Cifuentes (2009), según la cual "el contexto de conflicto armado acentúa las diferencias y las inequidades de género que tradicionalmente han caracterizado los ámbitos económicos, políticos y culturales" (p. 129), es pertinente plantearse varias preguntas alrededor de esta problemática:

¿Qué papel juegan las mujeres en las FARC? ¿Son en realidad partícipes de la lucha revolucionaria o son apenas un instrumento más de una estrategia que pretende mostrar unidad y legitimidad en torno a sus reivindicaciones marxistas-leninistas y que impone 
un ordenamiento de género para perpetuar patrones de dominación patriarcal sobre ellas?

Este artículo parte de la hipótesis de que las FARC, como ejército revolucionario, enarbola las banderas de la emancipación y búsqueda de igualdad de todos los ciudadanos. En ese contexto, ha incorporado mujeres para suplir necesidades del conflicto y darle legitimidad a su lucha, pero a pesar de emitir ese discurso, en el fondo ha establecido unos ordenamientos de género que estructuran relaciones de poder asimétricas. Las guerrilleras entran en una dinámica en la que quedan en lugares de subordinación a un mando militar jerárquico, creado y dirigido por hombres desde el nacimiento de la organización.

Para demostrarlo, este texto revisa, en primer lugar, las motivaciones de las mujeres que ingresan a las FARC. Más adelante se examinan las tareas que desarrollan dentro de la guerrilla y se analiza si estos roles corresponden a la búsqueda de igualdad o son apenas una expresión más de la cultura patriarcal que se reproduce en los grupos armados colombianos. Finalmente, se esbozan algunas reflexiones para tener en cuenta a la hora de diseñar políticas de reintegración que evalúen las afectaciones que tuvieron las mujeres durante su tránsito por la lucha armada. Una preocupación que debe ocupar el interés del Estado y la sociedad, máxime cuando se está desarrollando un proceso de negociación que aspira a la desmovilización de esta guerrilla, la más antigua de América Latina y la más grande del país.

En este trabajo se privilegiaron los testimonios de guerrilleras de las FARC — en armas y desmovilizadas - que se obtuvieron de manera directa a través de entrevistas, y otros presentes en libros y documentos que han recogido historias de vida de las combatientes. También se basa en la observación directa, por parte de la autora, de la vida de las mujeres en sus campamentos y en entrevistas que han entregado algunas guerrilleras con ocasión de los diálogos que se desarrollan en La Habana.

\section{ESTADO DEL ARTE}

En los últimos años ha surgido un especial interés por desentrañar la forma de vida de las guerrilleras de las FARC, a partir de la exposición pública y mediática que tuvo esta organización, especialmente durante los diálogos que se establecieron entre 1998 y 2002. La publicación de varios libros ha develado, aunque de manera anecdótica y a veces trivial, algunos aspectos de la vida de las mujeres en el monte. Esas publicaciones han servido de insumo para este artículo.

Periodistas como Patricia Lara, con su libro Las mujeres en la guerra, o Alfredo Molano, con Ahi les dejo los fierros, han hecho importantes aportes para revelar testimonios de mujeres combatientes, no solo de las FARC, sino también del ELN y las Auc. Arturo Alape, en su momento, reseñó en artículos publicados en El Espectador, la cotidianidad de las mujeres en las FARC. Hay un caso especial, el de Zenaida Rueda, la única guerrillera desmovilizada que se atrevió a contar su historia en un libro, Confesiones de una guerrillera, que se constituye en un recuento de sus 18 ańos en la guerrilla y está repleto de vivencias que merecen ser analizadas. 
Hay un interesante ejercicio que varias profesionales han hecho para aproximarse de manera académica a los testimonios de mujeres que militaron en los grupos guerrilleros que se desmovilizaron en la década de los noventa. Lo cotidiano y lo político de las mujeres en el EPL: historias de vida, de Marcela Sánchez y Claudia Sánchez, de la Universidad Nacional de Bogotá; La revolución o los hijos: mujeres y guerrilla, de Beatriz Toro, de la Universidad de los Andes; El componente de género en movimientos guerrilleros desde la percepción de excombatientes, de Victoria Eugenia Mosquera y Carmen Holguín, de la Universidad del Valle; Mujeres no contadas. Procesos de desmovilización y retorno a la vida civil de mujeres excombatientes en Colombia 1990-2003, de Luz María Londoño y Yoana Fernanda Nieto.

Todos estos trabajos se inscriben en la dinámica de contar y hacer visibles las preocupaciones de las mujeres que ya han dejado las armas. Pero van más allá de contar sus vivencias y dejan en evidencia las falencias de los procesos de desmovilización que no tuvieron en cuenta la perspectiva de género y, por tanto, sus reivindicaciones y temores no fueron tenidos en cuenta a la hora de planificar su retorno a la vida civil.

Estos análisis dejaron en su momento interesantes reflexiones e interrogantes sobre el papel de las mujeres en el conflicto, sobre los efectos que la militancia en la vida armada dejó en sus cuerpos y en sus mentes, y los problemas que tuvieron que afrontar para darle significado a una vida sin su ejército, sin el uniforme y sin las armas. Esas inquietudes siguen siendo válidas y pertinentes, y más cuando se habla de las FARC, la guerrilla más fuerte que subsiste en el país.

Por otro lado, se destacan los informes de organizaciones no gubernamentales o colectivos de mujeres que en los últimos años han reconocido que las colombianas no son solo víctimas del desplazamiento, el despojo o la violencia sexual como población civil, sino que también como combatientes son víctimas de otro tipo de violencias al interior de los grupos armados. En este rango se encuentran los informes de la Mesa de trabajo "Mujer y conflicto armado", de la Iniciativa de Mujeres por la paz, de la Relatora Especial de las Naciones Unidas sobre Violencia contra la Mujer, de Human Rights Watch, el Comité Internacional de la Cruz Roja, la Comisión Interamericana de Derechos Humanos, Amnistía Internacional, entre otros.

Otros textos interesantes, de corte autobiográfico, dejan también sembradas inquietudes sobre la vinculación política tras la desmovilización de dos excombatientes que ocuparon altos rangos en la guerrilla. Razones de vida, de Vera Grabe, o el de otra exintegrante del M-19, María Eugenia Vásquez, titulado "Diario de una militancia", que fue publicado en el libro Las violencias. Inclusión creciente.

Igualmente, a nivel regional se han hecho esfuerzos por ver la realidad de las mujeres, como el trabajo de Cristiane Lelievre y Graciliana Moreno, Haciendo memoria y dejando rastros. Encuentros con mujeres excombatientes del nororiente de Colombia, en Bucaramanga, o el de María Cristina Palacios, El conflicto armado y el desplazamiento forzado en Caldas: crisis de la institucionalidad familiar. 


\section{Género y conflicto armado}

Como bien lo resume Amani (2003) en un informe sobre este tema, al hacer un análisis del conflicto armado con base en los estereotipos, se alimenta la idea de que los hombres irán a la guerra y las mujeres los apoyarán desde el hogar:

La percepción popular es que los hombres son soldados o agresores y las mujeres son esposas, madres, enfermeras, trabajadoras sociales y trabajadoras sexuales. Es un hecho que son primordialmente los hombres a quienes se recluta y que mueren en las batallas, en tanto las mujeres conforman la mayoría de las bajas civiles y sufren en su función de cuidadoras. Sin embargo, las mujeres son además combatientes [...] Estas realidades tienen, para las relaciones de género, consecuencias que a menudo pasan inadvertidas y no son resueltas (p. 3).

Extrapolando esta reflexión al caso colombiano, Pino (2004) asegura que para el autoritarismo patriarcal, los hombres son los seres políticos, los guerreros, en oposición a las mujeres, consideradas defensoras de la vida pública y ajenas a los conflictos. "Esta supuesta distancia entre las mujeres y los contextos de guerra o los conflictos armados oculta una realidad que no deja mostrar a muchas mujeres participando en las actividades de la guerra también como protagonistas".

Si las mujeres están "naturalmente" impedidas para ejercer la violencia y se convierten, junto a niños y ancianos, en la población vulnerable, digna de recibir protección, se reproduce el modelo que Rojas (1998) ha denominado "las almas bellas y los guerreros justos", y que ha sido recogido por varios autores. Este modelo es el que impide hacer una valoración seria del papel que cumplen como combatientes.

Es interesante recoger la explicación de Butler (1999) en torno a que es a través de la repetición de actos, gestos y movimientos corporales como se crea el efecto de género. El comportamiento no depende de la identidad de género, sino que dicha identidad se obtiene mediante esas pautas culturales que sustentan las normas de género. El proceso de repetición sirve para una reconstrucción y legitimación de un conjunto de significados ya aprobados socialmente.

Para analizar el desempeńo de las mujeres en las filas hay que citar a Cockburn (1999), cuando explica que al enrolarse en los grupos armados las mujeres tienden a ubicarse en maniobras de subordinación política: "su compromiso activo en la guerra no trae la igualdad de las mujeres con los hombres [...] Ni consigue que el carácter, la cultura y la jerarquía de las fuerzas armadas se vuelva más femenino por la presencia de las mujeres" (p. 10).

\section{Las mujeres en las FARC}

En primer lugar, hay que señalar que en los estatutos y reglamentos internos de las FARC no se hace ninguna mención a las mujeres. De hecho, al hacer la descripción detallada de sus estructuras, en el capítulo ir del Estatuto se refiere a que las unidades están compuestas por "hombres". Más adelante, en capítulo IV, refiere: "Los deberes y derechos en las FARC-EP 
son iguales para todos sus integrantes pero sin igualitarismo pequeño-burgués" 5 .

De esta manera, las necesidades particulares de las mujeres quedan sepultadas bajo el análisis de clase. Las reivindicaciones de las guerrilleras se consideran "pequeñoburguesas" porque de alguna manera desvían la atención de la organización de su verdadero objetivo: la revolución.

A pesar de que en sus normas internas no hay ningún tipo de limitación para que las guerrilleras asciendan en la estructura militar, y de que el $40 \%$ de su fuerza es femenina, aún no hay mujeres en el Estado Mayor Central (de 31 miembros) ni en el Secretariado (7 miembros principales y dos reemplazantes), máximas instancias de dirección ${ }^{6}$.

No hay que perder de vista que el conflicto les dio a las mujeres la posibilidad de convertirse en sujetos políticos, de entrar a competir en un campo que antes era exclusivo de los hombres, de ejercer el derecho a desarrollarse en un ámbito que antes estaba cerrado para ellas. Pero también es importante destacar que el hecho de subvertir algunas de las categorías del orden de género que les habían sido asignadas en la civilidad, les ha traído conflictos al asumir su militancia.

Las FARC nacieron por iniciativa de un grupo de hombres que se internó en la montańa como autodefensa campesina. Los relatos que se conocen de boca de sus protagonistas ${ }^{7}$ destacan la valentía y el heroísmo de esos campesinos que abrieron trocha y resistieron la embestida de las tropas oficiales. Las mujeres no están presentes en estos relatos. Hay una referencia en el libro Ahi les dejo los fierros, de Alfredo Molano (2009), de boca de Desconfianza, miembro de esas autodefensas campesinas.

En las autodefensas no había mujeres. Algunas nos ayudaban a hacer inteligencia, pero combatientes de fusil y canana, solo la mujer del finado Vencedor, La Negra. Era muy arrecha, muy franca para el combate. Era tolimense. No se le quedaba a nada. Siempre detrás de su macho. Peleaba de verdad. Andaba con un mero revólver porque su puesto era de mando. Peleó en Cabrera, se atrincheró en la Vuelta de la Muerte, atacó a un combo del Ejército y le mató ochenta hombres (p. 25).

Se destaca la referencia que hace Desconfianza acerca de que estaba "siempre detrás de su macho", y el énfasis que hace en que La Negra fue la excepción; la regla era que las mujeres ocuparan otro lugar en esas luchas. Las primeras mujeres en las FARC fueron las esposas de aquellos 48 campesinos que gestaron el grupo insurgente y huían con ellos cargando al hombro los hijos y animales de corral para sobrevivir. En el archivo del diario $E l$ Espectador reposa un reporte de 1964, que no

5 Tomado de una publicación clandestina que se les entrega a los guerrilleros al momento de ingresar a la organización.

6 Datos suministrados por fuentes directas de las FARC y confirmados con fuentes de inteligencia militar.

7 Arturo Alape y Alfredo Molano han escrito varios libros en los que relatan el surgimiento de las FARC, con testimonios de primera mano de sus fundadores. Textos de la guerrilla han hecho lo propio. 
se publicó en su momento ${ }^{8}$, del corresponsal en Neiva en el que da cuenta de la captura de una mujer, Clementina Cruz, reseñada como colaboradora de Tirofijo, a quien "le prestaba servicios como cocinera y lavandera", y que su marido, Darío Mejía, "les prestaba el servicio de médico, era yerbatero". Clementina reveló detalles de Domitila Ducuara, la compañera sentimental del jefe guerrillero, quien "dirigía el personal femenino (que podía ser de 15 mujeres)" y les "imponía trabajos, las castigaba, ordenaba turnos para la vigilancia de los castigos, las arrodillaba con piedras en las manos o las ponía a hacer barro".

La dinámica del conflicto y las condiciones sociales de la población fueron llevando a las mujeres a empuñar las armas. No hay una fecha que marque el incremento en su incorporación, pero en el libro de Patricia Lara (2011), Las mujeres en la guerra, Olga Marín?, una las guerrilleras más destacadas en las FARC, a pesar de no haber tenido mando militar, da una pista al respecto. $\mathrm{Al}$ referirse al día que llegó a la guerrilla, en noviembre de 1981, aseguró: "Cuando empezamos a desempacar comenzaron a aparecer hombres por todos lados. Ahí había un curso de autodefensa para unos sesenta hombres. Y además había como
30 guerrilleros, de los cuales solo dos eran mujeres. Y llegamos tres mujeres nuevas. [...] En el frente 16 éramos cuatro mujeres" (p. 104).

Testimonios de guerrilleros con más de veinte años de militancia en las FARC, coinciden en afirmar que después de los diálogos de paz que se desarrollaron con el Gobierno entre 1982 y 1986, se notó un incremento en la incorporación de mujeres a la organización ${ }^{10}$. "Para 1993, las FARC logran tener 60 frentes guerrilleros que incluyen, además, todas las estructuras urbanas, las guardias especiales del secretariado y de los integrantes del Estado Mayor Central" (Medina Gallego, 2006, p. 155).

\section{Las razones de la incorporación}

Como afirma Barth (2002), las necesidades de la guerra y la ideología de los grupos armados pueden acelerar la incorporación de mujeres en las filas. Asegura que cualquier ejército revolucionario que lucha por liberar a las masas de la opresión imperialista, debe tener como objetivo la emancipación de la mujer.

La base principal de un grupo revolucionario es reunir todas las fuentes disponibles para hacer su lucha. Para

8 El 1 de junio de 2008, un breve extracto del reporte fue utilizado para una publicación titulada "Las viudas que dejó Manuel Marulanda”.

9 Su verdadero nombre es Liliana López. Hizo parte de un contingente de estudiantes citadinos que ingresó a las FARC a comienzos de los años ochenta. Fue la compañera sentimental de Raúl Reyes y miembro de la Comisión Internacional de la organización. En estos momentos está licenciada y vive en Cuba.

10 En esta época las Farc experimentan un proceso de expansión, fruto de la creación de la Juventud Comunista (JUCO), de la fortaleza del movimiento sindical, del triunfo de la Revolución cubana y de la represión estatal que llevó al monte a una cantidad importante de militantes. 
lograrlo, la ideología es una herramienta indispensable. La movilización y politización de las masas femeninas es vital para su éxito. Como dijo Lenin: el éxito de una revolución depende del alcance que tengan las mujeres que en ella participan (p. 12).

Judith Butler (1999) ha señalado que la feminidad y la masculinidad no son características naturales y que, por el contrario, son categorías que se aprenden y se practican a diario con actividades cotidianas, con la socialización, con la relación con el otro. Explica que de manera voluntaria o, incluso por la fuerza, el género refuerza y recuerda la posición que ocupa cada uno en la estructura de poder.

En el caso de la incorporación de individuos a un grupo armado, se inicia un proceso de socialización para aprender los códigos de la guerra y adaptarse a la nueva vida. Hombres y mujeres deben comenzar a desaprender aquellas categorías que la sociedad les confirió y aprender otras para sobrevivir en la organización. En el caso de las mujeres, este proceso puede generar traumatismos que los hombres no experimentan.

Para los varones, el ingreso a una organización político-militar les significa reforzar los valores y las categorías que la sociedad ya les había conferido: fuerza, decisión, arrojo, valentía. Para las mujeres, en cambio, elementos como la maternidad, las relaciones de pareja, la intimidad, la vida y la muerte, adquieren un valor diferente. Ellas deben modificar de manera sustancial los referentes que culturalmente les habían sido asignados.

Es lo que Vásquez (2000) ha llamado "proceso de aculturación", que implica para las mujeres realizar cambios profundos en su identidad de género, para adherirse, no sin conflicto, a la cultura hegemónica masculina presente en los grupos insurgentes.

Los testimonios de las mujeres que han pertenecido a un grupo armado en Colombia aluden reiteradamente a una vida, en la civilidad, marcada por los maltratos y la subyugación a la autoridad patriarcal. Falta de acceso a educación, violencia intrafamiliar y sexual, trabajos forzados, son comúnmente referenciados, sobre todo por aquellas que ya se han desmovilizado. Eso no significa que no haya algunas que ingresaron por otras razones, como una vinculación familiar a la lucha armada, por su trabajo como líderes sociales, por una militancia política que les ha ocasionado persecución.

En todo caso, sin importar las razones que hayan tenido para ingresar, a las mujeres se les motiva a incorporarse con la ideología marxista de la lucha de clases. Se les conmina a luchar contra la opresión, se les promete un cambio en sus condiciones de vida cuando triunfe la revolución, y se genera la expectativa de que ellas, al empuñar un arma, podrán hacer parte de ese cambio.

No se trata de inferir que todas las mujeres fueron engańadas y que su ingenuidad las llevó a caer en una trampa. Se trata de una oportunidad que se les presenta, sobre la cual pueden decidir, algunas con mayor autonomía que otras, pero que al final les ofrece la posibilidad de hacerse sujetos políticos, de darle un significado a su vida, de empoderarse, de vincularse a un proyecto colectivo.

Es revelador en este punto el testimonio de una guerrillera que ingresó a los 14 años, 
luego de que su hermana mayor se enrolara, buscando huir de un tío que abusaba de ella:

A mí me fue gustando esa vida. Una se veía elegante con camuflado y más con fusil. Darcy comenzó a hacerme carantońas y un día me rendí y le pedí ingreso a la mujer que comandaba las comisiones que arrimaban a mi casa y que por nombre de guerra se llamaba Karina. Era fuerte, seria, pero quería mucho a mi hermana y, de paso, a mí (Molano, 2009, p. 46).

En su estudio con mujeres desmovilizadas entre 1990 y 2003, Londońo y Nieto (2006) comparan las razones que llevaron a hombres y mujeres a vincularse a un grupo armado. Un $28 \%$ de las mujeres considera que la razón para ingresar fue la afinidad política, frente al $26 \%$ de los hombres. Cuando se les interroga sobre otras razones, el $46 \%$ de las mujeres aduce haberlo hecho por situaciones conflictivas en su hogar, frente al 26\% de los hombres. El 56\% de las mujeres dijo haber entrado por resentimiento con algún grupo armado y apenas el $7 \%$ de los hombres argumentó esta motivación. El $48 \%$ de las mujeres dijo haberse enlistado por razones económicas, frente al $25 \%$ de los hombres.

El análisis de estas cifras muestra el contraste. Es evidente que la situación en sus hogares, los problemas económicos y la sed de venganza las mueve más a ellas que a ellos a entrar a la guerrilla. La militancia política no es la razón principal.

Ya dentro del grupo, las mujeres encuentran un ordenamiento de género que no difiere mucho del que había en su comunidad. El hecho de someterse a una estructura jerarquizada, dominada por hombres, en la que sus intereses se pierden bajo el manto de la homogeneización del grupo, a la práctica de rutinas tendientes a disciplinarlas y adiestrarlas en lo militar, y a una fuerte estigmatización, hace que las relaciones de poder entre géneros al interior del grupo armado se parezcan al ordenamiento que hay fuera de él.

Scott (1996) explica que aunque la hegemonía masculina no esté en disputa, en contextos de conflicto, el género es una forma persistente y recurrente de facilitar la significación de poder. El testimonio de Karina ${ }^{11}$ (Castrillón, 2009b), la mujer que más alto rango militar ha logrado en las FARC, cobra gran significado. Al ser interrogada sobre las razones por las cuales logró ser comandante de frente, respondió:

Eso se lo debo a la crianza que me dieron mis viejos. Ellos me enseñaron a ser trabajadora y muy obediente. Para mí no fue difícil cumplir órdenes, no me daba pereza. Desde que ingresé supe comportarme; mi papá me dijo: no se porte mal porque le va mal. Si me mandaban a la guardia, a recoger leńa, yo lo hacía inmediatamente. Los mandos tienen en cuenta eso.

11 Karina llegó a ser comandante del frente 47 y desertó de las FARC en mayo de 2008. Sobre ella pesan órdenes de captura por terrorismo, homicidio, rebelión y secuestro extorsivo. El Gobierno le encargó, como gestora de paz, la tarea de motivar más deserciones entre sus excompañeros de lucha. 
El gran mérito de Karina para ascender fue su obediencia y sumisión al mando. Pero no el único. "Cuando me dieron mando como reemplazante de escuadra [la unidad más pequeña, 12 guerrilleros] me propuse demostrarles a estos muchachos que no me iban a degradar, me preparé para el combate" (Castrillón, 2009b). Sus buenos resultados militares y el carisma con la tropa la ayudaron a escalar hasta comandar un frente (entre 120 y 200 guerrilleros).

Karina fue una de las figuras más mediáticas en la guerrilla. Los organismos de seguridad del Estado la calificaron de "cruel y sanguinaria”. Los miembros del ejército que participaron en combates contra ella la señalaban como una mujer ruda, que "parecía un macho"12, mientras la responsabilizaban de históricos golpes contra la fuerza pública ${ }^{13}$. En su momento, el presidente Álvaro Uribe le puso precio a su cabeza: 1500 millones de pesos (Defensa, 2005).

Con base en este testimonio, en el análisis de Barth (2002) acerca de los conflictos africanos, y de los aportes de Blair y Londoño (2003) podrían hacerse varias reflexiones. La afirmación de que las mujeres son violentas o crueles corresponde a que ellas tienen la característica de ser "más violentas que los hombres", o se trata de un calificativo otor- gado porque no es "natural" que ellas asuman las mismas actitudes que los hombres, es decir, están transgrediendo el lugar y la caracterización que les asignó el modelo patriarcal.

Las propias guerrilleras se ufanan de la fama que se han granjeado entre el enemigo. Mery ${ }^{14}$, comandante de escuadra, lo admite:

En la guerrilla las mujeres son de respeto. En el ejército dicen que somos más decididas y más metelonas. Yo soy buena para el combate, me gustan las armas. Yo puedo hacer lo que me propongo. A mí los muchachos me retaban en el combate y cuando veían que yo era mejor que ellos, se callaban. Es que en la pelea se sabe quién es quién (Castrillón, 2009a).

Sara, una excombatiente de Eritrea, citada por Barth (2002), cuenta orgullosa que "las mujeres son tan agresivas como los hombres. De hecho las mujeres eran más agresivas que ellos" (p. 18). La autora se pregunta si las mujeres reaccionan más violentamente que los hombres en una situación de conflicto, y luego concluye aduciendo que la evidencia empírica sugiere que las mujeres no son menos ni más belicosas que los hombres. Es solo que la inclinación de estas hacia la fuerza va en contravía de los roles tradicionales. Para analizar estos juicios de valor, es interesante citar a Karina:

12 Testimonios recogidos de manera informal entre miembros del Ejército, periodistas y población civil que la conocieron en su papel de combatiente.

13 Informes de inteligencia militar y recopilación de archivos de prensa donde reposan declaraciones del alto mando militar y otras fuentes estatales.

14 Nombre de batalla. La entrevista se realizó pocos días después de su desmovilización y a punto de dar a luz su primer hijo. Ella dice que se entregó porque no quiso abortar. 
Las mujeres somos fieras en el combate para no quedarnos atrás de los hombres. Un hombre flojo no se nota, pero una mujer floja todos la ven. Si uno tiene mando no puede demostrar miedo, si le hieren o le matan gente, lo juzgan a uno más duro que a los varones (Castrillón, 2009b).

Testimonios de mujeres excombatientes en grupos tan diversos como los movimientos de liberación africana, las guerrillas centroamericanas de El Salvador y Nicaragua, los Montoneros de Argentina, el grupo separatista vasco ETA, las guerrillas de los Tigres Tamiles o las Viudas Negras chechenas, hacen referencia al esfuerzo que tienen que hacer para demostrar que son "iguales a los hombres" en el campo militar. Dejan de ser ellas porque quieren ser como los hombres.

Susana Téllez ${ }^{15}$, una de las guerrilleras que hacía parte de la guardia personal de Raúl Reyes, habló así de su entrenamiento: "Uno se prepara política, militar y moralmente, uno sabe que no va a enfrentarse con niñas en un reinado de belleza, que va a una confrontación de hombre a hombre, somos verracas para enfrentarnos" (Emanuelsson, 2005).

\section{Asimetría en la práctica}

Las guerrilleras coinciden en resaltar que mujeres y hombres cumplen las mismas fun- ciones y explican que los hombres cocinan y lavan la loza y la ropa, y que ellas cargan leña y van al combate. Aun así, reconocen que hay machismo dentro de las FARC. Lo que pareciera ser una contradicción, lo único que hace es explicar que así las tareas asignadas a hombres y mujeres sean similares, eso no significa que los roles y las relaciones de poder sean simétricos.

Todo lo contrario. Lo que demuestra es que a pesar de que ellas se esfuercen por "igualarse" a los hombres, no logran llegar a las máximas instancias de poder de la organización. Las mujeres se incorporan a una organización político-militar que tiene establecidas unas jerarquías y ellas se ubican en posiciones de subordinación. Como señala Cockburn (1999) "su compromiso activo en la guerra no trae la igualdad de las mujeres con los hombres. Ni consigue que el carácter, la cultura y la jerarquía de las fuerzas armadas se vuelva más femenino por la presencia de las mujeres".

Victoria Sandino ${ }^{16}$, la figura más visible de la delegación femenina de las FARC en La Habana explica que la guerra les imponen mayores barreras a las mujeres por las exigencias y las condiciones de vida extrema. "No por el valor —insiste ella— sino porque nuestros cuerpos son distintos" (Castrillón, 2015). Y hace énfasis en que cuando falla la planificación y se presentan los embarazos, las

\footnotetext{
15 Susana sobrevivió al bombardeo de la Operación Fénix, el 1 de marzo de 2008. Hoy vive en Nicaragua, en calidad de refugiada.

16 Su nombre de pila es Judith Simanca Herrera. Ella hace parte de las 15 mujeres que integran la Delegación de Paz de las FARC, que en total está conformada por 40 personas. Estas citas hacen parte de una entrevista que contestó vía correo electrónico.
} 
guerrilleras se ven enfrentadas a la disyuntiva de abortar o dar a luz, de continuar en la organización o abandonarla para cumplir el rol de madres.

"Esto, en la práctica, hace que nosotras mismas vayamos limitando nuestra carrera en una guerra tan prolongada" (Castrillón, 2015). Pero también reconoce que otra de las razones por la cuales las mujeres no acceden a las instancias de poder de la guerrilla es el sistema de educación patriarcal, en el que las mujeres no son formadas para dirigir. Aun así, aclara que al interior de sus filas están tratando de superar esa situación.

Declaraciones similares han dado otras guerrilleras presentes en La Habana. Todas ellas desmienten que la organización las obligue a abortar o las castigue por no interrumpir el embarazo, y hacen énfasis en la igualdad de oportunidades para desempeñar roles y ascender. Con ocasión de los diálogos abrieron su propia página web $^{17}$, en la cual incluyen testimonios que resaltan la valentía de las mujeres que las precedieron y les rinden tributo a las heroínas que murieron en combate.

A pesar de que las guerrilleras activas insistan en que tienen las mismas oportunidades que los hombres para ascender, las que ya dejaron las armas reconocen que existen muchas barreras que se los impiden. Zenaida Rueda (2009), quien escribió un libro relatando sus vivencias, contó una anécdota que pone en evidencia las relaciones asimétricas de poder:
Marquetalia tendría unos 80 años. No tenía tropas bajo su mando, sino una guardia personal que le asignó Jojoy. Lo respetaban mucho porque comenzó en la guerrilla junto con Marulanda, pero a él se le pasó el tiempo y nunca lo promovieron a comandante. Dicen que conseguía mujer y era la mujer la que mandaba [...] y en la guerrilla cuando una mujer manda al hombre, así sea antiquísimo, Jojoy lo deja relegado (p. 72).

La experiencia de Karina es reveladora para confirmar la manera como se ejerce y se mantiene el poder en las FARC:

Cuando llegué al mando del frente 47 tuve dificultades con los miembros de la dirección y comandantes de rango medio. Ellos no querían que yo los mandara. Me hicieron quedar mal con el mando superior, eso me hizo renunciar a la dirección. Al final ese fue un detalle para que decidiera mi desmovilización (Castrillón, 2009b).

La insistencia de las guerrilleras en el sentido de que hay "igualdad" porque todos cumplen las mismas funciones, solo deja ver que en el fondo existe una distribución de funciones basada en estereotipos que disimula la preponderancia del poder masculino. Aunque, en teoría, las tareas se reparten con base en las habilidades de los combatientes, los varones creen que ser radista ${ }^{18}$, enfermero o secretario no es para ellos. Las mujeres, respondiendo a esos códigos implícitos, suelen inclinarse por estas actividades. $\mathrm{Al}$ respecto, Cockburn (1999) plantea que:

\footnotetext{
17 www.mujerfariana.org

18 Así se denomina a la persona que opera el radio o equipo de comunicaciones con el cual el comandante de la unidad se comunica con el mando o con otras estructuras.
} 
La invisibilización del género es la rareza que necesita explicación. Se deriva de una relativamente reciente y poco convencional ideología de la igualdad sexual, cuyos expositores dicen da lo mismo si usted es una mujer o un hombre [...] Este es un ideal importante. Pero el despliegue del concepto a menudo oscurece el hecho de que en la práctica la diferenciación de género y el poder masculino se mantienen vivos (p. 2).

La regulación de los más íntimos detalles de la vida cotidiana de los combatientes es asumida por las mujeres como necesaria para mantener la disciplina, pero aceptan que les impacta. Sonia ${ }^{19}$, quien hizo parte de la dirección del frente 14, reconoce: "Es muy diferente estar en la vida civil donde uno va para donde quiere... Aquí todo cambia, hasta para ir a los orinales o cualquier otra parte, todo tiene que ser por permisos. Uno empieza a chocar" (Alape, 1999).

\section{Los cuerpos para la guerra}

En las FARC, hombres y mujeres pueden elegir libremente una pareja ocasional con la cual pasar una noche o una pareja estable. En ambos casos, deben obtener autorización del comandante de la unidad. Esta situación, que en el papel suena pragmática y liberal, esconde, sin embargo, la discriminación basada en estereotipos. Podría decirse que en las trincheras se desarrollan los mismos códigos sexistas que imperan afuera. Las mujeres que eligen compañeros sexuales ocasionales terminan estigmatizadas. Aquellas que eligen una pareja estable, son bien valoradas como combatientes. Rueda Calderón (2009) lo explica así:

Hermides lo primero que me advirtió fue que no conversara mucho con las mujeres porque eran muy chismosas y después hacían algún comentario sobre mí y me metían en problemas y me dañaban la hoja de vida. Me decía que las mismas guerrilleras me inducían a la prostitución, porque se iban al baño y se ponían a hablar de que tal guerrillero estaba bueno, que esta noche me voy a acostar con tal (p. 126).

Karina habla de promiscuidad: "Hay viejas muy relajadas, duermen con el uno y con el otro, con el que les ofrece cualquier prebenda, un champú” (Castrillón, 2009b). Esto nos muestra que el cuerpo de la mujer sigue siendo el dispositivo para justificar una relación asimétrica de género. El cuerpo se transa, se negocia. La ruptura con el modelo patriarcal en el que a las niñas se le enseña a mantenerse vírgenes y que su proyecto de vida gira en torno a la maternidad, genera relaciones conflictivas entre ellas.

Cifuentes (2009) lo plantea en un interesante artículo:

Las guerrilleras sufren con mayor crudeza las consecuencias de las relaciones de pareja desiguales e injustas. El aura de heroísmo que adquieren los hombres conduce con frecuencia a la promiscuidad masculina y a la paternidad irresponsable. Adicionalmente, las mujeres pierden no solo la potestad, sino también todo contac-

19 Su nombre de pila es Anayibe Rojas Valderrama. Fue capturada y extraditada a Estados Unidos, donde purga una condena de 11 ańos de prisión por narcotráfico. 
to con sus hijos. [...] si bien causa traumas tanto a las madres como a los padres, en últimas es vista como algo justificable "por la causa” en el caso de los hombres, pero imperdonable cuando se trata de una mujer (p. 137).

El cuerpo es además su herramienta para la guerra y eso le da otro significado. Las mujeres refieren lo difícil que resulta el entrenamiento militar. En los testimonios aluden a largas marchas con pesados morrales por montañas, ríos y selvas. Soportar estas pruebas físicas no es un obstáculo para ellas. Por el contrario, para la mayoría es un reto, una oportunidad para demostrar que son capaces de hacer lo mismo que los hombres y así lograr reconocimiento en el grupo. Zenaida Rueda (2009) cuenta que los cursos de ascenso se imparten igual para hombres y mujeres: "Hacíamos flexiones de pecho, cuclillas, ejercicios muy duros. Entrenamos 15 días, no nos dejaban comer mucho, el baño era rapidito, cinco minutos de aseo y teníamos que estar otra vez en el patio, con ropa limpia y buena presentación" (p. 43).

Para Beatriz Toro (1994), el uniforme tiene también un significado especial en estos conflictos de identidad y relata que cuando tienen que sacar a un combatiente del campamento, al hombre simplemente lo afeitan, mientras que a las guerrilleras tienen que "disfrazarlas de mujer": "Mientras en el caso de ellos no hay rupturas con el modelo de identidad de género, en el de ellas su participación las obliga a asimilarse a un mundo altamente masculino en términos de los valores que lo caracterizan (fuerza, resistencia, dominio, heroísmo) [...] deben disfrazar su feminidad" ( p. 82)
Pero no se trata solo del uniforme. El portar un arma genera un poder que solo es visible cuando ya no la tienen. Este testimonio es un referente para dimensionar lo que sucede tras la desmovilización:

... andar desarmado era sentirse un objetivo, un blanco, o lo que también llaman una diana. Me sentía suelta, desorientada y hasta sin futuro. No me acostumbraba a moverme sin el peso del fusil. Me despertaba y buscaba el frío del cańón, el gatillo, la culata. Había entregado mi poder, estaba entregada. Sin el fierro era casi otra persona, nadie. Una pesadilla. Ya no dependía de nadie, nadie me daba órdenes, nadie me mandaba. Sentía un hueco día y noche. Sin armas, ¿̇e quién dependía? ¿Cómo podía defenderme? Ya no existían ni mandos ni tinieblos, ni mozos ni maridos. Estaba sola y desocupada por dentro (Molano, 2009, p. 65).

\section{CONCLUSIONES}

Las declaraciones analizadas evidencian que a las mujeres se les invita a hacer parte de un proyecto revolucionario que pregona igualdad de clases pero que no tiene intenciones de cambiar las relaciones asimétricas de poder que las mantienen en posición de subordinación. Todo indica que las nińas y adolescentes que ingresan a las FARC, lo hacen en su mayoría buscando emancipación y reconocimiento, $y$ que adentro se estrellan con una realidad que las relega a un papel secundario, sin opciones de llegar a los escaños más altos de poder, a pesar de ser el $40 \%$ de la fuerza en armas.

Durante su militancia armada, la concepción tradicional de elementos como la sexualidad y la maternidad fue sustancialmente alterada, sin que esto significara un cambio en 
el orden de género. Por el contrario, este orden sirvió para confirmar la oposición binaria virginal/impura. Esos nuevos roles sirvieron para establecer y perpetuar una distribución asimétrica del poder, manteniendo a las mujeres en posición de subordinación.

Revisando los testimonios de mujeres que han pertenecido a grupos guerrilleros en Centroamérica, el Cono Sur, África o Colombia, queda en evidencia que para ellas esa militancia significó la oportunidad de vincularse a un proyecto político colectivo, de demostrarse a sí mismas y a un conjunto que son capaces de penetrar en ámbitos históricamente dominados por hombres. Pero también les ha dejado rupturas que son difíciles de subsanar. La primera es con su propia identidad, con la manera de verse y sentirse mujeres.

Después de pasar por un entrenamiento militar, de protagonizar actos considerados como de "crueldad" o "barbarie", que riñen con la imagen femenina construida, y de esculpir y disciplinar sus cuerpos para la guerra, cerrándole las puertas a la maternidad, estas mujeres se enfrentan a una sociedad que las juzga por su pasado violento, por el abandono de los hijos o los abortos practicados y que, además, las obliga a situarse en las funciones y roles tradicionales, relegándolas a la esfera privada ${ }^{20}$.
En su trabajo, Londońo y Nieto (2006) arrojaron bastantes luces al respecto, al contar que las guerrilleras que se desmovilizaron en los años noventa no estuvieron presentes, en la mayor parte de los casos, en la negociación ni en la firma de los acuerdos de paz. El caso del M-19, que contaba con dos mujeres en la dirigencia, también es muy revelador: en desarrollo de la reincorporación, no se aprobó la idea de lanzar una lista al Congreso conformada solo por mujeres ${ }^{21}$.

El actual proceso de diálogo que se adelanta en La Habana está cambiando sustancialmente la historia de la participación de las mujeres en una mesa de negociación. Aunque las delegaciones de las dos partes arrancaron con una abrumadora mayoría de plenipotenciarios hombres ${ }^{22}$, con el pasar del tiempo, y gracias a la fuerte presión del movimiento de mujeres en Colombia, tanto Gobierno como FARC terminaron incluyendo mujeres en sus equipos principales.

El nivel de participación ha subido tanto que hoy existe una Subcomisión de Género, que viene trabajando en la inclusión de la perspectiva de género en los tres puntos ya acordados y en los que vienen, y en la Subcomisión Técnica del Fin del Conflicto, que discute temas gruesos como el cese al fuego

20 Las mujeres que pertenecieron a la guerrilla salvadoreña han expresado frustración porque en los Acuerdos de Paz no se incluyeron espacios ni recursos para ellas.

21 Al final, Vera Grabe encabezó una lista a la Cámara de Representantes por Bogotá que obtuvo más de 30.000 votos.

22 El Gobierno presentó a Elena Ambrosi. Las FARC no tenían a ninguna mujer como negociadora plenipotenciaria, a pesar de que exhibieron a Alexandra Narińo, más conocida como Tanja, la holandesa, en ruedas de prensa y eventos públicos. Ella nunca se desempeñó como negociadora principal. 
bilateral y definitivo, y el proceso de desarme, desmovilización y reintegración (DDR).

Las FARC, por su parte, están haciendo un esfuerzo por cambiar su imagen con respecto al rol de las mujeres en la organización. De hecho, sacan a relucir que su equipo está conformado por 15 mujeres y 25 hombres, es decir, casi la misma representación que tienen las mujeres en la tropa, cercana al $40 \%$ del total.

No es la primera vez que Colombia se enfrenta a un proceso de desmovilización masiva de combatientes ${ }^{23}$, pero de concretarse el proceso de paz que se adelanta en La Habana, tal vez será la oportunidad en la que un número importante de mujeres deje las armas, por tanto, se hace necesario tener en cuenta los roles asumidos por ellas en el conflicto y las distorsiones que su militancia pueden dejar en su reconocimiento como mujeres.

Por ello, es importante plantear si las actuales políticas de reinserción están diseñadas para recomponer los vacíos y las rupturas que las mujeres manifiestan sentir una vez dejan un colectivo (la guerrilla) que supuestamente les entrega poder y reconocimiento a través de un uniforme y un arma. ¿ $\mathrm{O}$ se trata de un programa que ofrece oportunidades de formación, capacitación y puesta en marcha de proyectos productivos, que intenta hacer un "borrón y cuenta nueva", que no les permite sanar heridas y proyectarse como mujeres en un escenario diferente?
Se debe llamar la atención en el sentido de que los programas gubernamentales no se pueden circunscribir a entregarles oportunidades laborales sin ahondar en las razones que las llevaron a empuñar las armas y sin conocer la verdad sobre lo que sucedió con sus vidas y sus cuerpos durante la militancia armada. Solo así se darán medidas que garanticen la no repetición.

La mesa de negociación debería ir más allá de fijar pautas para la concentración de las fuerzas guerrilleras y el desarme con miras a terminar el conflicto. Debería plantear el papel que pueden jugar las mujeres en ese escenario concreto y en la implementación de los acuerdos. Asimismo, el Estado debería plantearse la necesidad de garantizarles a las excombatientes la posibilidad de recuperar a sus hijos abandonados o arrebatados en el fragor de la guerra para que puedan rehacer sus familias truncadas y le encuentren sentido a sus vidas, a pesar de que la sociedad que las acoge tiene otras representaciones distintas del ser mujer.

Estas reflexiones son más que pertinentes hoy de cara a un proceso de paz que se adelanta con esta guerrilla y que aun no deja ver de manera concreta en qué sentido está incluyendo la perspectiva de género en los acuerdos y su implementación. Se vuelve más que necesario recordar el llamado que hace el Consejo de Seguridad de la Organización de Naciones Unidas, a través de la Resolución

23 Presidencia de la República señala que las mujeres representaron entre el 24 y $27 \%$ de los desmovilizados de los grupos guerrilleros en los ańos noventa. 
1325, que invita a los Estados a incorporar esta mirada en los procesos de negociación, reincorporación a la vida civil y construcción y mantenimiento de la paz.

\section{REFERENCIAS}

Alape, A. (1999). Al miedo no le hicieron pantalones. El Espectador.

Amani, E. J. (2003). Género y conflictos armados. Londres: Institute of Development Studies.

Barth, E. (2002). Peace as disappointment. The reintegration offemale soliders in post-conflicts societies: $A$ compartive study from Africa. Oslo: International Peace Research Institute (PRIO).

Blair, E. y Londoño, L. M. (2003). Experiencias de guerra desde la voz de las mujeres. Nómadas, 19.

Butler, J. (1999). El género en disputa. México: Paidós.

Cifuentes, M. R. (2009). La investigación sobre género y conflicto armado. Eleuthera, 127-164.

Cockburn, C. (1999). Género, conflicto armado y violencia politica. Washington D.C.: Cuadernos INER, Universidad de Antioquia.

Emanuelsson, D. (2005). Anncol. Recuperado de: http://pazfarc-ep.blogspot.com/search?updated$\max =2012-11-28 \mathrm{~T} 08: 48: 00-05: 00 \& \max -$ results $=10 \&$ start $=80 \&$ by-date $=$ false

Lara, P. (2011). Las mujeres en la guerra. Bogotá: Planeta.

Londoño, L. M. y Nieto, Y. F. (2006). Mujeres no contadas. Procesos de desmovilización y retorno a la vida civil de mujeres excombatientes en Colombia 1990-2003. Medellín: La Carreta Editores E.U.

Medina Gallego, C. (2006). FARC-EP, notas para una historia politica 1958-2006. Bogotá: Universidad Nacional de Colombia.

Meertens, D. (2000). Género y violencia. Representaciones y prácticas de investigación. En Robledo, Á. y Puyana, Y. Ética, masculinidades y femini- dades. Bogotá: Facultad de Ciencias Humanas, Universidad Nacional de Colombia.

Melo Moreno, M. A. (2006). La categoría analítica de género: una introducción. En S. Y. Grupo de Estudios en Género, De mujeres, hombres y otras ficciones. Género y sexualidad en América Latina (pp. 33-38). Bogotá: Tercer Mundo Editores y Universidad Nacional de Colombia.

Ministerio de Defensa (2005). Fuerza Aérea Colombiana, FAC. Recuperado de: www.fac.mil.co

Molano, A. (2009). Ahi les dejo los fierros. Bogotá: Aguilar.

Molyneux, M. (1980). ¿Mobilization Without Emancipation? Women's Interests, the State, and Revolution in Nicaragua. Voice of Eritrean Women, newspaper of the NUEW.

Pino, A. C. (2004). El patriarcado y sus manifestaciones en el conflicto armado. Asociación de Hombres por la Igualdad de Género. Recuperado de: http:// www.fire.or.cr/marzo02/repem.htm

Rojas de Ferro, M. C. (1998). Las almas bellas y los guerreros justos. En En otras palabras... Mujeres, guerra y paz. Bogotá: Grupo Mujer y Sociedad, Universidad Nacional de Colombia, Corporación Casa de la Mujer de Bogotá y Fundación Promujer.

Rueda Calderón, Z. (2009). Confesiones de una guerrillera. Bogotá: Planeta.

Scott, J. W. (1996). El género: una categoría útil para el análisis histórico. En Lamas, M. El género: la construcción cultural de la diferencia sexual (pp. 265-302). México: PUEG.

Toro, B. (1994). La revolución o los hijos (Tesis de grado para optar al título de Antropóloga). Universidad de los Andes, Facultad de Ciencias Sociales y Humanidades, Departamento de Antropología, Bogotá. 
Vásquez, M. E. (2000). La vida se escribe en borrador y se corrige a diario. Efectos del conflicto armado en mujeres excombatientes. Taller "Género, conflicto y construcción de la paz sostenible". Bogotá.

\section{Entrevistas}

Castrillón, G. (2009a). Cómo ascender en las FARC. Entrevista a Mery.

Castrillón, G. (2009b). Cómo ascienden las mujeres en las FARC. Entrevista a Mosquera.

Castrillón, G. (2015). El papel de las mujeres en la Delegación de Paz de las farc. Entrevista a Simanca Herrera. 